\title{
ADAPTATION TO CLIMATE CHANGE BASED ON FARMERS'PERCEPTION: A STUDY ON INDIGENOUS HILLS CULTIVATORS IN NAGALAND, INDIA
}

\author{
Niranjan Roy $^{1}$, Avijit Debnath ${ }^{1}$ and Sunil Nautiyal ${ }^{2}$ \\ ${ }^{1}$ Department of Economics, Assam University, Silchar-788011, Assam, India \\ ${ }^{2}$ Centre for Ecological Economics and Natural Resources (CEENR), Institute for \\ Social and Economic Change (ISEC), Nagarabhavi, Bangalore - 560 072, India
}

*Corresponding Author Email id: roy_niranjan@yahoo.com

Received: 4.10.2020; Revised: 28.10.2020; Accepted: 4.11.2020

(C)Society for Himalayan Action Research and Development

\begin{abstract}
Climate change is believed to have severe impacts on different sectors of an economy especially the agricultural sector. The adverse impact of climate change, however, can be mitigated if farmers have awareness and better level of adaptive responses. This study examines the perception of farmers belong to indigenous communities in the state of Nagaland of Northeast India on climate change and analyzes their adaptation responses to climate change. A hundred and twenty farming households were interviewed during July and August 2019. The study employed the Heckman sample selection model to analyse the two- step process of adaptation to climate change. Farmers' perception of climate change was significantly related to the age of the head of the household, level of education, and past experience of drought and flood. On the other hand, adaptation to climate change is determined by education of household head, economic status, and access to credit, type of cultivation, non-farm income, farming experience, distance to market, and past experience of climatic hazard.
\end{abstract}

Keywords: Adaptive response, Climate change, Heckman sample selection model, Indigenous Communities, Naga tribe, Nagaland

\section{Introduction}

Climate change is believed to have severe impacts on different sectors of an economy especially the agricultural sector. This is because higher temperatures, reduced rainfall and increased rainfall variability reduce crop yield and hence threaten food security. The northeastern states of India in general and Nagaland in particular are highly dependent on agriculture for livelihood. According to an estimate, Nagaland has registered significant decline in monsoon rainfall in recent years (Government of India, 2015). Among the 100 districts vulnerable to climate change in India, three of them belong to Nagaland (Venkateswarlu et.al. 2011). These changes will certainly make economic development of the State more difficult and challenging. Under these circumstances, it is immensely important to know how farmers perceive climate change which in turn shall guide necessary polices to be implemented for promoting successful adaptation to fight the maladies of climate change.

The main objective of the present work is to identify the major factors and quantify the extent to which the identified factors influence perceptions and adaptation to climate change in state of Nagaland.

\section{Methodology}

Description of the study area: The study was conducted in the state of Nagaland, one of the eighth states of Northeast India. Nagaland which 
is mostly hilly located between $25^{\circ} 6^{\prime} \mathrm{N}$ and $27^{\circ} 4^{\prime} \mathrm{N}$ latitudes and between $95^{\circ} 20^{\prime} \mathrm{E}$ and $95^{\circ} 20^{\prime} \mathrm{E}$ longitudes spans $16,579 \mathrm{sq} \mathrm{km}$ with an estimated population of over 1.5 million. Doyang, Dikhu and Dhansiri, are the main rivers draining the state and the climate is sub-tropical to sub-temperate. The most part of the state is generally characterised by heavy rainfall baring a few districts. Due to the influence of the southwest monsoon, the state sees most of the rainfall during the fourth months of June-September. About 90\% of the populations are Schedule Tribes belonging to five groups viz. Naga, Kuki, Kachari, Garo and Mikir. Naga community is the major tribe consisting $98 \%$ of total population and inhibited by 16 major sub-tribes distinct in character from the others in terms of customs, languages and dresses. About $70 \%$ of the total population of the state depends on farming. The Naga tribes practice both jhuming and terrace cultivation. Though often considered primitive and unproductive, Jhum is a complex agricultural system that is well adapted under certain conditions, which require exhaustive comprehension of the environment to succeed. Shifting cultivation covers about $75 \%$ of the total arable area of the State. The system of shifting cultivation entails a number of stages. In the first stage, forest bushes are slashed to the stump level in the months of December-January and small trees and bamboos are felled while short tree stumps and large tree boles are left alone. intact. In the second stage, the stumps are allowed to dry enough so that they can be burnt easily. After the burning is done, the land is cleared and prepared for sowing. In the third stage, seeds of different crops as desired by the farmers are planted before the onset of the rains. Once the crop is harvested for one or two repeated seasons, the area is left idle for a number of years and the cultivator moves to a new area to cultivate crops by the aforsaid slashing and burnning nethod. The jhum cycle used to last as long as 25 to 30 years. But it has shortened considerably to 4 to 5 years due to rapid increases in the tribal population. In earlier days, long cycles were possible because pressure of population was very low and land was available in plenty (Singh et.al.,2003). With the shortening of the jhum cycle, there has been impact on energy ratio of output and input and ultimately effects economic return of the farmer (Ramakrishnan, 1991).

\section{Sample Design and Data}

The study has adopted a multi stage stratified random sample technique to collect data. In the first stage we have classified the entire Nagaland into two categories (strata): Drought prone districts and other districts (Venkateswarlu et.al., 2011). In the second stage, Dimapur has been selected from the first category and Kohima has been selected from the second category using random statistical technique. Kuhuboto block and Dhansiripar block from Dimapur have been selected purposively in the third stage as because these two blocks constitutes the higher proportion of shifting cultivations in the district. Similarly, we have purposively selected Jakhama \& Sechu Zubza blocks from Kohima for the similar reason. In the fourth stage, Phuhoto and Disagaphu villages from the selected blocks of Dimapur and Phesama \& Khonoma villages from the selected block of Kohima have been randomly selected. Finally, from each village 30 households were selected randomly from the complete lists of farmers. In this ways, a sample of 120 households were selected from the two districts for Nagaland. All the selected villages are inhabited by indigenous Naga communities practicing shifting cultivation to a great extent. Primary data on socio economic and demographic variables, area and productivity of crops, type of cultivation, access to credit, farming experience, livelihood pattern and adaptive strategies to climate change etc., were collected using the pre-tested and structural schedule through personal interview of the households during July and August 2019.

\section{Analytical Technique}

There are two stages to adaptation to climate change. In the first stage, farmers perceive whether there is any change in climatic condition or not. In the second stage, they decide whether or not to adapt by taking a particular measure. This leads to a sample selectivity problem, since 
only those who perceive climate change will adapt, whereas we need to make an inference about adaptation by the agricultural population in general (Maddison, 2007). Therefore, to correct this selection bias, we have used Heckman's sample selectivity model The model for sample selection assumes that an underlying relationship exists, the latent equation given by $y_{j}^{*}=x_{j} \beta+u_{1 j}$

Such that we observe only the binary outcome given by the probit model as

$y_{j}^{\text {probit }}=\left(y_{j}^{*}>0\right)$

The dependent variable is observed only if $\mathrm{j}$ is observed in the selection equation

$y_{j}^{\text {select }}=\left(M_{j} \theta+u_{2 j}>0\right)$

$u_{1} \sim N(0,1)$

$u_{2} \sim N(0,1)$

$\operatorname{corr}\left(u_{1}, u_{2}\right)=\delta$

Where $\mathrm{x}$ is a vector of independent variables which influence farmers adaptation to climate change, $M$ is an vector of regressors which influence perception, $\mathrm{u} 1$ and $\mathrm{u} 2$ are error terms. When $\delta \neq 0$, the standard probit techniques applied to equation (1) yield biased results (Deressa et.al., 2006). Thus, the Heckman probit provides consistent, asymptotically efficient estimates for all parameters in such models. Thus, the Heckman two stage selection model was employed to analyze the perception and adaptation to climate change .

\section{Results and Discussion}

\section{Farmers' Perception about Climate Change}

When asked if they have ever heard of what 'Climate Change' means from any source, around $93 \%$ of the respondent said that they have heard about the term mostly from television.

The findings from the farmer's perceptions regarding changes in the climate are shown in figure-1. As we can see more than $90 \%$ of the respondents are of the opinion that the temperature has been increasing in the locality. Not even a single respondent stated that temperature trend in the state has been decreasing, while about $3 \%$ of the respondent in Kohima claimed to have noticed no change. The farmers' assessment agreed with the scientific studies on temperature trend in the northeast India (Das et. al., 2019; Ravindranath et. al., 2011).

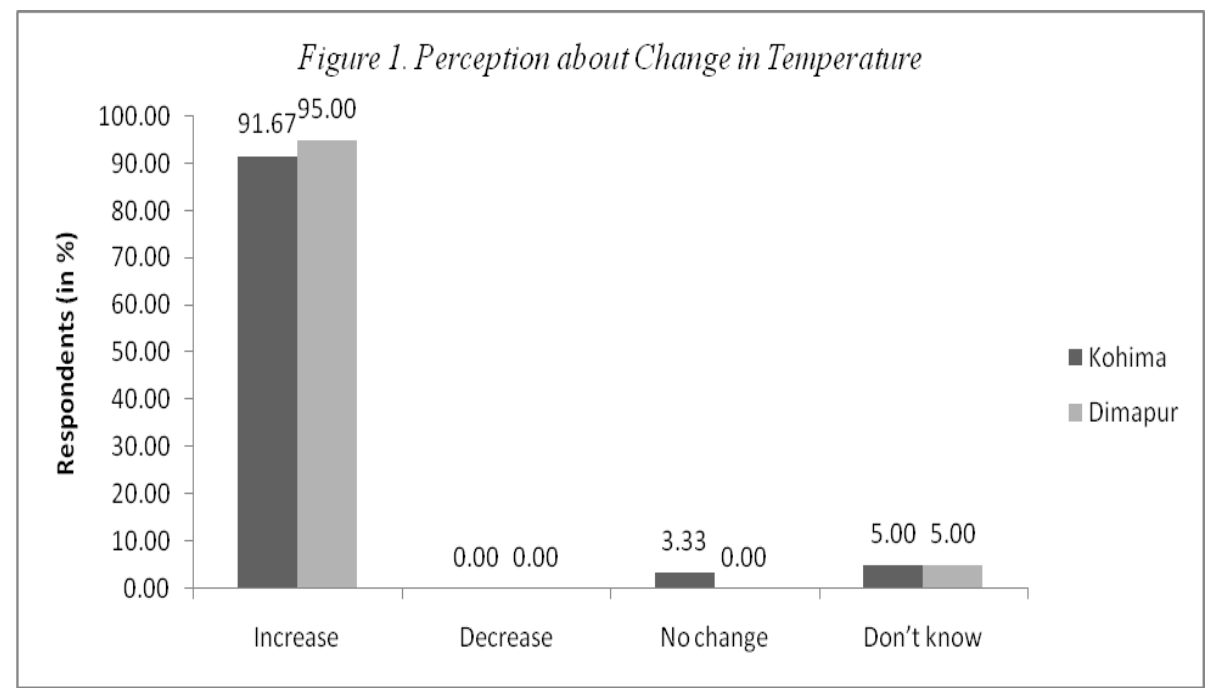

Source: Compiled from Field Survey, 2019

The distribution of the respondents according to their assessment of rainfall trend in the area is presented in figure-2. Majority of the respondents in both districts (about 87\% in Kohima and 93\% in Dimapur) claimed that rainfall trend has been decreasing. About 3\% respondents in Kohima are 
of the opinion that there is no change in precipitation while the figure is zero in Dimapur. Finally, around $10 \%$ respondents in Kohima and
7\% respondents in Dimapur claimed not to have noticed any change in rainfall trend in the area.

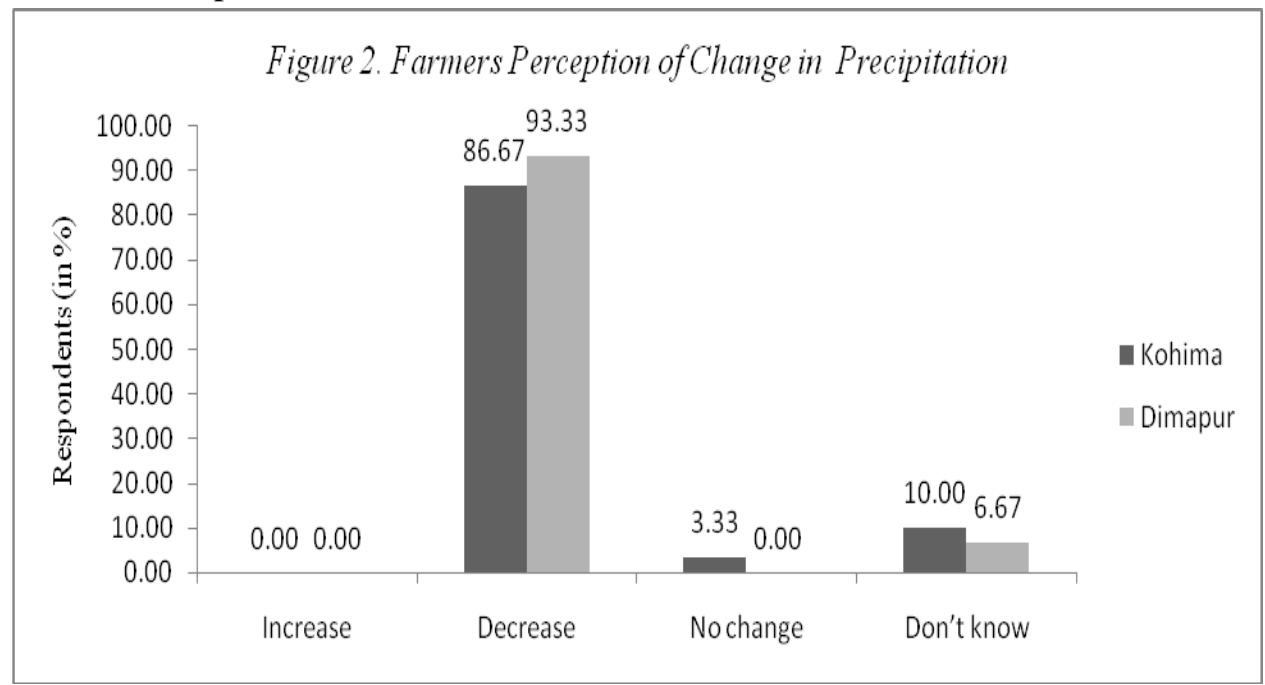

Source: Compiled from Field Survey, 2019

The trend in the onsets of monsoon has been examined among respondents and the distribution is presented in figure-3. The distribution reveals that most of the respondents in both the districts
(75\% in Kohima and $82 \%$ in Dimapur) claimed to have noticed delay in the onset of monsoon in the area, while about $12 \%$ in Kohima and 5\% in Dimapur claimed to have noticed timely onset of monsoon.

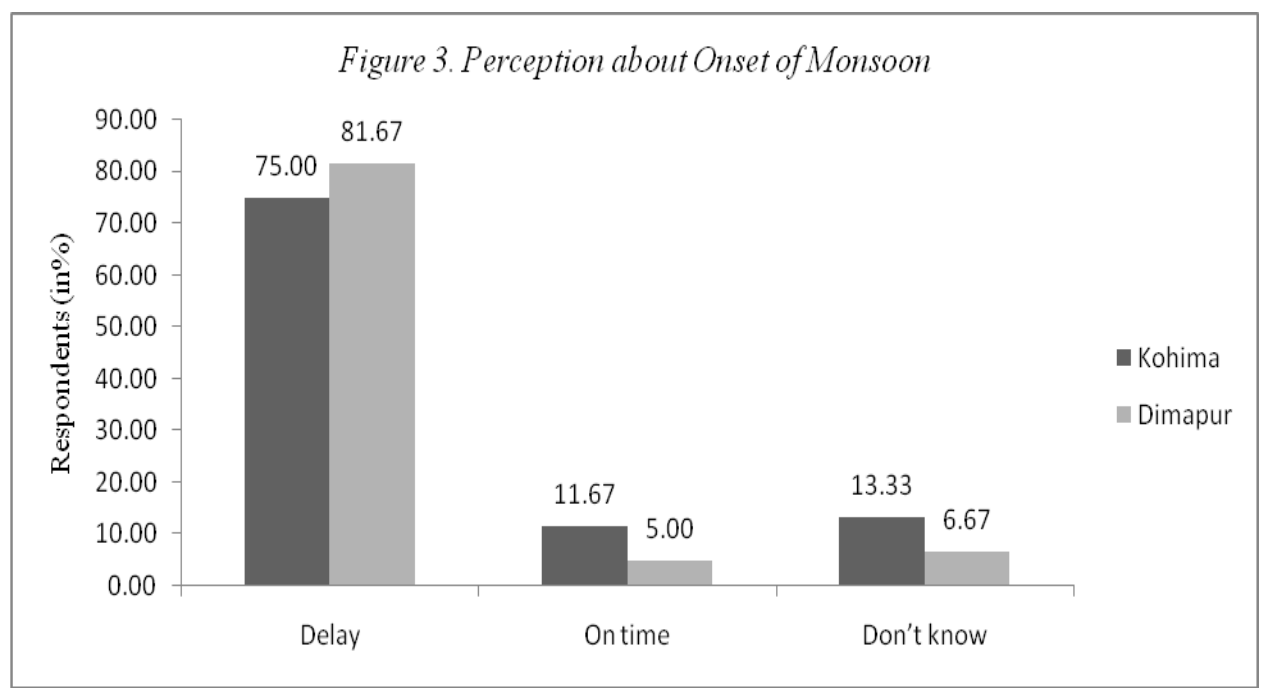

Source: Compiled from Field Survey, 2019

When we asked the respondents to state reasons for climate change, responses varied from climate change being caused by factories and industries (36.67 \%) to it being God's work (6.67\%). Respondents who felt that climate change was due to increasing use of vehicles are around $32 \%$. Almost $5 \%$ of the respondents did not know the reasons for climate change (figure 4). However, what is important to note here is that none of the respondent considered shifting cultivation as the cause of climate change. When we raise this issue in the focused group discussion, they reveal that the way shifting cultivation is under taken in the Khonoma village is distinct and unique in nature. Unlike others, Angami community farmers of Khonoma village have perfected the practice of alder based jhum cultivation into a fine art. The 
alder tree has root nodules which improve soil fertility by fixing atmospheric nitrogen into the soil. It also enhances crop yields and reduces soil erosion. Therefore, shifting cultivation in Khonoma village is rather considered helpful for forest ecosystem. It was learnt that some of the nearby villages are trying to follow the traditional practices of Khonoma village for sustaining shifting cultivation with efficient resource management.

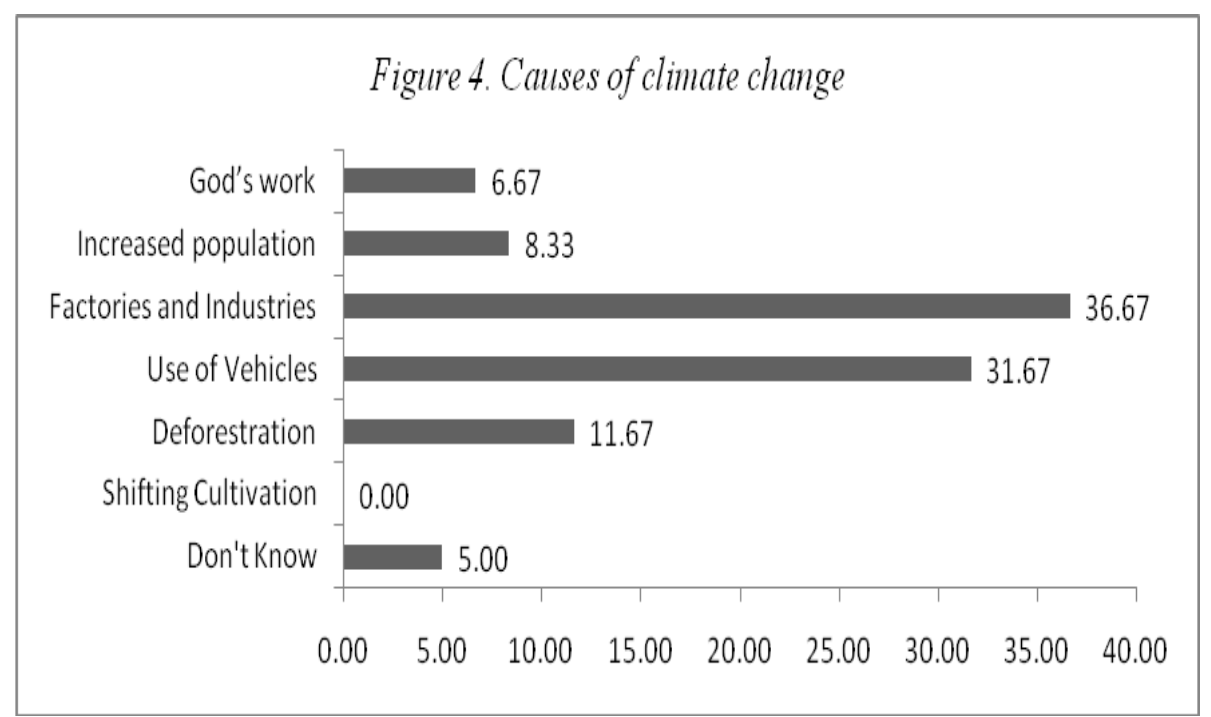

Source: Compiled from Field Survey, 2019.

\section{Farmers' adaptive responses}

In order to understand the adaptive responses of farmers we have asked if they had responded through adaptation to reduce the negative impacts of climate change. Here we have limited our inquiry among those farmers who claimed to have observed changes in climate over the past 20 years. Our investigation reveals that around 68 percent of the farmers have adopted one or more of the major adaptation options which include crop management, water management, land management, and changing planting dates (see figure 5).

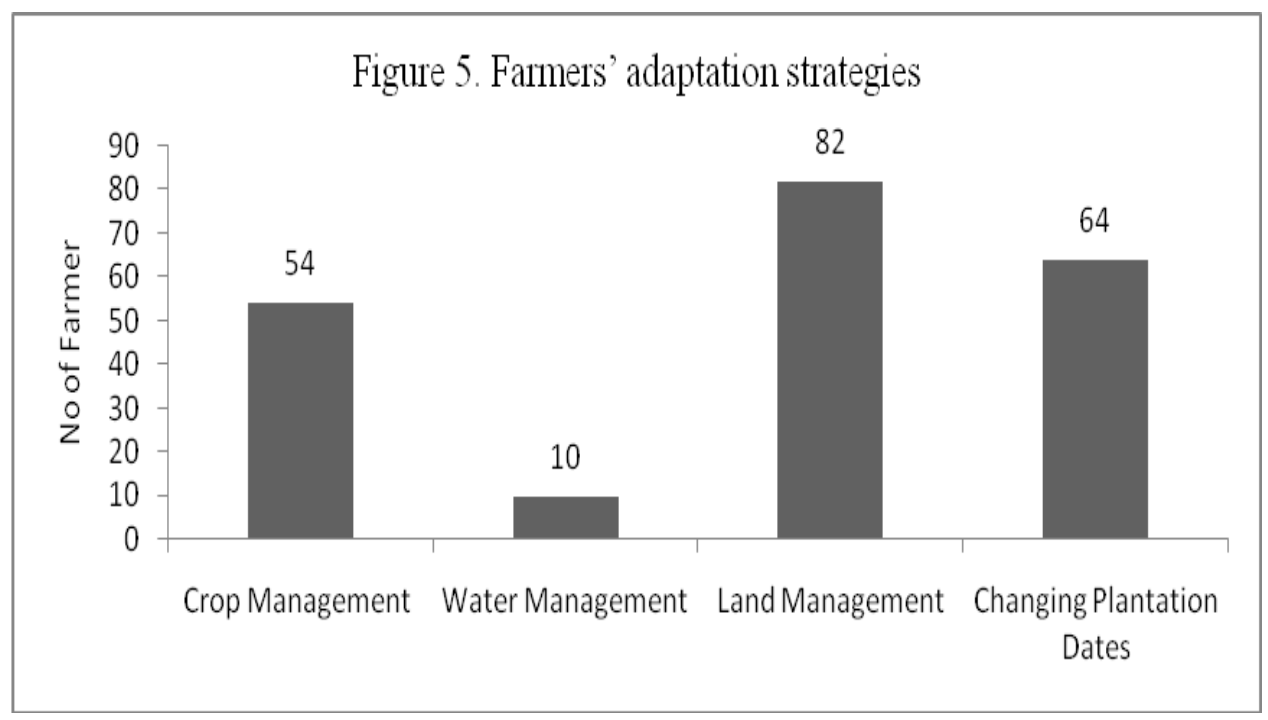

Source: Field Survey, 2019

As we can see, most of the farmers have adapted land management as a strategy to climate change. Under land management, they mainly resort to terrace settled cultivation in place of shifting cultivation. Changing plantation date as per weather condition is found to be the second 
major adaptive strategies marginally followed by crop management. A tiny percentage of farmers have adapted water management to fight water scarcity particularly during winter. Farmers who perceived climate change but failed to adapt gave many reasons as barriers to adaptation, which included high cost of adaptation, non-suitable for local cultivation, lack of information on adaptation methods, and knowledge for adaptation.

\section{Determinants of perception and adaptation}

As mentioned in section III, we have used Heckman Two stage model to identify the determinants of perception and adaptation to climate change. The first stage of the Heckman probit model considers whether the farmer perceived a climate change; this is the selection model. The second-stage model looks at whether the farmer tried to adapt to climate change, and it is conditional on the first stage, that is, a perceived change in climate. This second stage is the outcome model (Deressa et. al., 2006).

The dependent variable for the selection of equation is whether a farmer has or has not perceived climate change. The explanatory variables for the selection of equation include different socio-demographic and environmental factors based on the survey of literature. It is hypothesized that the age, education of the head of the household, access to media, and past experience of climatic hazard influence the awareness of farmers to climate change.

The dependent variable for the outcome equation is whether a farmer has adapted or not to climate change. The explanatory variables are chosen based on the climate change adaptation literature and data availability. These variables include: education of the head of the household, dependency ratio, gender of the head of the household, non-farm income, economic status, access to credit, cultivation type, farm size, distance to nearest market, experience, past experience of flood or drought. Selection of these explanatory variables is inspired by a study conducted by Hassan \& Nhemachena (2008). A detailed description of these variables is reported in Appendix 1.

We begin the analysis by testing suitability of the Heckman probit model its explanatory power over the standard probit model. The test results indicated the presence of sample selection problem (dependence of the error terms from the outcome and selection models) justifying the use of Heckman probit model with rho significantly different from zero (Wald $\chi^{2}=10 \cdot 91$ with $\mathrm{P}=$ 0.001). Moreover, the likelihood function of the Heckman probit model was significant (Wald Wald $\chi^{2}=78.41$ with $\mathrm{P}=0.001$ ), showing its strong explanatory power.

Given the appropriateness of the Heckman model, we reported the results of the selection and outcome models in Tables 1 . As we can see, most of the explanatory variables and their respective marginal values are statistically significant in determining perception and adaptation in a direction that would be expected ${ }^{1}$. Results of the selection of the model for the wet lowland condition (Table 1) indicate that education level of the household head, age of the household head, past experience of drought or flood in significantly increase the likelihood of farmers' perception of climate change $(\mathrm{P}<0.01)$. However, access to media though has positive sign for its coefficient is not statistically significant. The results from the outcome model, which analyses the factors affecting adaptation, indicated that most of the explanatory variables considered in the present study are statistically significant. Variables that positively and significantly influenced adaptation to climate change include education of the head of the household, economic status, distance to nearest market, access to credit, type of cultivation and past experience of drought and flood. On the other hand, dependency ratio, and non-farm income are negatively associated with adaptation. Finally, the coefficients of gender

\footnotetext{
${ }^{1}$ It may be noted that marginal effects measure the expected changes in the probability of perception and adaptation with respect to a unit change in an explanatory variable.
} 
and farm size are found to be statistically insignificant.

Based on the model results, marginal effects of explanatory variables are computed. The computed marginal effect for education variable showed that one additional year in educational status of the household head increases the probability of adaptation by $12 \%$. This clearly indicates the importance of education to fight the climatic hazard. We attribute this positive relation to the spillover effects that education brings in terms of access to information on improved technologies and land management. This finding is consistent with available literature (Igodan et.al. 1988; Lin, 1991; Deressa et.al., 2006). Secondly, farmers' adaptive measures decreases by $1.8 \%$ for a unit rise in dependent member in the household.
Thirdly, the probability of adaptation is $35 \%$ lower for the farmers belonging to below poverty line category. This signifies the fact that poorer farmers are at higher risk of climate change and therefore requires special treatment. Likewise, the probability of adaptation increases by $9.8 \%$ when farmers have access to credit. This finding is quite expected given the fact that adaptive measures are not a free gift of nature. In order to adapt necessary measures to cope up with the changing climate, one has to spend money on land management, technology and irrigation. Since farmers in general are not a big saver of their income, they do need easy credit facilities to bring changes. This finding is also supported by available literature (Deressa et.al. 2006; Gbetibouo, 2009).

Table 1: Regression Results: Heckman Two- Stage Model

\begin{tabular}{|c|c|c|c|c|}
\hline \multirow{2}{*}{$\begin{array}{l}\text { Explanatory } \\
\text { Variables }\end{array}$} & \multicolumn{2}{|c|}{ Adaptation Model } & \multicolumn{2}{|c|}{ Selection Model } \\
\hline & Coefficients & Marginal Values & Coefficients & Marginal Values \\
\hline Constant & $2.814 * * *$ & & & \\
\hline Age & & & $0 \cdot 018^{*}$ & $0.006^{*}$ \\
\hline Education & $0.361 * *$ & $0.129 * *$ & $0.021 * * *$ & $0.007 * * *$ \\
\hline Dependency Ratio & $-0.058^{*}$ & $-0.018^{*}$ & & \\
\hline Gender & 0.491 & 0.147 & & \\
\hline Economic Status & $1.151 * * *$ & $0.315^{* *}$ & & \\
\hline Access to Media & & & 0.053 & 0.012 \\
\hline Access to Credit & $0.318 * *$ & $0.098 * *$ & & \\
\hline $\begin{array}{l}\text { Type of Cultivation } \\
\text { (Ref. Settled) }\end{array}$ & $0.871 * * *$ & $0.363 * *$ & & \\
\hline Non-farm income & $-0.031^{*}$ & $-0.012 *$ & & \\
\hline Farm Size & -0.651 & -0.199 & & \\
\hline Distance to Market & $-0.071 * *$ & $-0.003 * *$ & & \\
\hline Experience & $0.027 * *$ & $0.013^{*}$ & & \\
\hline Past Experience & $0.013 * * *$ & $0.004 * * *$ & $0.086^{*}$ & $0.026^{*}$ \\
\hline Total observations & 120 & & & \\
\hline Censored & 30 & & & \\
\hline Uncensored & 90 & & & \\
\hline $\begin{array}{l}\text { Wald Chi square } \\
\text { (Zero slopes) }\end{array}$ & $\begin{array}{c}78.41 \\
\mathrm{P}=0.001\end{array}$ & & & \\
\hline $\begin{array}{l}\text { Wald Chi square } \\
\text { (independent } \\
\text { equations) }\end{array}$ & $\begin{array}{c}10.91 \\
\mathrm{P}=0.001\end{array}$ & & & \\
\hline
\end{tabular}

Note: $* * *, * *$ and $*$ indicate significance levels at $1 \%, 5 \%$ and $10 \%$, respectively 
Similarly, farmers who are more involved in settled cultivation has $36 \%$ more probability of adapt measures for climate change than their counter parts. This is possible because in settled cultivation, farmers are more emotionally attached to their land. Besides, settled cultivation being private in nature enables farmers to bring in easy changes in respect of technology adoption. However, non-farm income reduces the probability of adaptation by about $1.3 \%$ showing that as income from non-farm source increase dependences on farming decreases which in turn reduces motivation to invest for adaptation in the crop sector. Similarly, a unit rise in distance to nearest market reduces the probability of adaptation marginally by $0.3 \%$. In line with study by Nhemachena and Hassan (2007), we observed that the probability of adaptation increases by $1.3 \%$ for a unit rise in farming experience. Finally, farmers who have a past experience of drought or flood have a higher probability of adaptation than their counter parts.

\section{Conclusion}

Climate change is supposed to have serious socio economic consequences on, on rural peoples whose livelihoods depend largely on nature. This paper makes an attempt to understand perception and adaptation to Climate change in Nagaland state of India using primary data through field survey. The study indicates that farmers are well aware of climate change, but only $68 \%$ took some adaptation measures to reduce its impact. This study employed the Heckman sample selection model to explore determinants of perception and adaptation to climate change. Results from Heckman model reveal that education of household head, economic status, access to credit, type of cultivation, non-farm income, farming experience, distance to market, past experience of drought and flood all have significant impact on adaptation to climate change. Gender of the household head and farm size did not significantly influence adaptation measures in the study area.
Therefore, government policies should consider these factors to enhance the chances of farmers' adaptive measures in order to minimize adverse effects of climate change on agricultural production. It is necessary for the government to ensure that terms for credit facilities are simple enough to encourage farmers to go for institutional credit, which will in turn increase their ability to change crop and soil management strategies in response to climate change. Similarly, farmers should be motivated further for settle cultivation through training and extension service. In his model of CPR, Dasgupta (2005) has shown that privatisation of the grazing land and cooperation over the use of that land as a CPR involves trust. Community ownership and distribution of jhum lands by village council is acting efficiently on the perception of mutual trust. On the basis of mutual trust and confidence, the traditional community institutions have grown over the centuries. These institutions are now sceptical about unsustainable nature of shifting agriculture and they are aware of its negative impact on ecology and environment. For improved efficiency in functioning of the local level institutions, the National Forest Commission of the Government of India asked for strengthening customary institutions (Sule, 2006). Effective public policy need to be devised for strengthening traditional community institutions for management of common resources like, empowering community institutions, provision for landownership rights, identification of CPR, strengthening extension services, provision for institutional credit facilities etc.

\section{Acknowledgements}

The authors duly acknowledge the financial support of ICSSR, New Delhi, India for Research Programme on "Climate Change, Dynamics of Shifting Agriculture and Livelihood Vulnerabilities in Northeastern States of India" during 2018-20. 


\section{Appendix 1}

\begin{tabular}{|c|c|c|}
\hline Variables & Definition & Type of Variable \\
\hline $\begin{array}{c}\text { Perception to Climate } \\
\text { Change }\end{array}$ & $\begin{array}{l}1=\text { if the head of the ith household perceive that } \\
\text { there is change in climatic condition during the last } \\
20 \text { years, } 0=\text { otherwise. }\end{array}$ & Binary \\
\hline $\begin{array}{l}\text { Adaptation to Climate } \\
\text { Change }\end{array}$ & $\begin{array}{c}1=\text { if the ith household has adapted strategies to } \\
\text { climate change, } 0=\text { otherwise. }\end{array}$ & Binary \\
\hline Age & Age of household head in years & Continuous \\
\hline Education & Completed years of schooling of household head & Continuous \\
\hline Dependency Ratio & $\begin{array}{l}\text { Number of dependents aged zero to } 14 \text { and over the } \\
\text { age of } 65 \text { in the household }\end{array}$ & Continuous \\
\hline Gender & $1=$ if the household head is male, $0=$ female & Binary \\
\hline Economic Status & $\begin{array}{c}1=\text { if ith household belong to APL family, } 0=\text { BPL } \\
\text { family }\end{array}$ & Binary \\
\hline Access to Media & $\begin{array}{c}1=\text { if the ith household has access to media. , } 0= \\
\text { otherwise }\end{array}$ & Binary \\
\hline Access to Credit & $\begin{array}{c}1=\text { if ith household has access to institutional } \\
\text { credit, } 0=\text { otherwise }\end{array}$ & Binary \\
\hline $\begin{array}{l}\text { Type of Cultivation (Ref. } \\
\text { Settled) }\end{array}$ & $1=$ settled cultivation, $0=$ otherwise & Binary \\
\hline Non-farm income & Monthly average income in Rupees & Continuous \\
\hline Farm Size & Farm size in acre of land & Continuous \\
\hline Distance to Market & Distance in Kilometer & Continuous \\
\hline Experience & Farming experience of household head in years & Continuous \\
\hline Past Experience & $\begin{array}{l}1=\text { if the ith household has faced drought or flood in } \\
\text { the last } 20 \text { years, } 0=\text { other wise }\end{array}$ & Binary \\
\hline
\end{tabular}

Note: APL stands for above poverty line category, and BPL stands for below poverty line category.

\section{References}

Das A, Ghosh, P K, Choudhury, B U, Patel, D P, Munda, G C, Ngachan, S V, \& Chowdhury, $P$ (2019) Climate change in North East India: Recent facts and events-worry for agricultural management, In: Proc.Clim. Chan. Agri. 32-37.

Dasgupta, P, (2005) Common Property Resources: Economic Analytics, In: Teaching Workshop on Environmental Economics for the Middle East and North Africa, December 5-16, ICTP, Trieste, Italy

Deressa, TT, Hassan, R, Ringler, C, Alemu, T, and Yesuf, $M$ (2006) Determinants of farmers' choice of adaptation methods to climate change in the Nile Basin of Ethiopia. Glob. Env. Chan. 19(2): 248-255.
Gbetibouo, GA, (2009) Understanding farmers' perceptions and adaptations to climate change and variability: The case of the Limpopo Basin, South Africa (Vol. 849), Intl Food Policy Res Inst.

Hassan RM and Nhemachena, C (2008) Determinants of African farmers' strategies for adapting to climate change: Multinomial choice analysis, Afr. J Agri. RES Eco. 2(3112016-5521): 83-104.

Igodan CO, Ohaji, PE, and Ekpere, JA (1988) Factors associated with the adoption of recommended practices for maize production in the Kainji Lake Basin of Nigeria, Agr. Adm. Ext. 29(2): 149-156.

Lin JY, (1991) Education and innovation adoption in agriculture: evidence from hybrid rice in China, Am. J. Agr. Eco. 3(3): 713-723. 
Maddison D (2007) The perception of and adaptation to climate change in Africa, (The World Bank).

Nhemachena, C, and Hassan, R, (2007). Microlevel analysis of farmers' adaption to climate change in Southern Africa, Intl Food Pol. Res Inst.

Ramakrishnan, PS (1991) Ecology and Sustainable Development, (National Book Trust, India).

Ravindranath, NH, Rao, S, Sharma, N, Nair, M, Gopalakrishnan, R, Rao, A S, \& Krishna, N (2011) Climate change vulnerability profiles for North East India, Curr. Sci, 384-394.

Singh, J, Borah, IP, Barua, A, Barua, KN (2003) Shifting Cultivation in North East India- An Overview. Rain Forest Research Institute, http:// www. rfri.org / rpap23.htm.

Sule, S, (2006) Jhum Cultivation under Sharper Scrutiny, (http://www. India together.org/2006/dec/agr-jhum.htm).

Venkateswarlu B, Kumar, S, Rao, SDCS, Kokate, KD, \& Singh, AK (2011) Demonstration of Climate Resilient Technologies on Farmers' Fields, Action Plan for 100 Vulnerable Districts. National Initiative on Climate Resilient Agriculture, Central Research Institute for Dry land Agriculture, Hyderabad. 